\title{
Køn, litterær kvalitet og presset fra medierne \\ Kanondebatten i kulturhistorisk lys
}

\section{Af Karen Klitgaard Povlsen}

et historisk vue, der antyder rammerne for en kvalitetsdiskussion, som forbindes med nationaltænkning og dyrkelse af de nationale sprog. Det sidste forbindes med en kønstænkning, hvor faderskab og moderskab ændrer sig radikalt i borgerskabet omkring 1800. De nye forestillinger om modersmålet og moderens rolle $\mathrm{i}$ alfabetiseringen af de små poder knytter kvinden til ordet og følelserne, mens mænd fortsætter arbejdet med produktion af kunst og anden værditilvækst. Denne kønsdistribution rokkes i middelklassen i slutningen af 1800-tallet, da de læsende kvinder selv for alvor begynder at skrive (og male) for at genopstå i en anden form omkring 1900, hvor der inden for litteraturen sker et modernistisk skred med en afstandtagen til den realistiske kunst og litteratur og de nye massemediers populære fortællinger og billeder. Det kulminerer i dada og surrealisme og ekstreme formeksperimenter bl.a. inspireret af den nye psykoanalyse. Det var været svært for 
mange kvinder at bryde gennem denne modernisme-mur og blive anerkendt som en del af den nationale arv eller kanon. Dette var et afsæt for kvindelitteraturforskningen fra 1970erne og frem. I dag tegner der sig et billede, hvor kvalitet, nationstænkning, køn, medier og modernisme krydser ind over hinanden på en måde, der gør det svært ikke bare for kvinder, men for alle margin-mærkede grupper at nå frem til et kvalitetsstempel som kanonisering. Det grundlæggende spørgsmål er dog: Hvad skal vi med kanon?

Et ofte brugt argument i den standende kulturkamp for etablering af kanonlister inden for de forskellige kunstarter er nødvendigheden af at have fælles referencerammer i en 'kultur' som den danske. Åbenbart mener mange, at de eksisterende referencerammer er truede. Det truende er knyttet til det populære, det massekulturelle, det 'fremmed'-sprogede, det ikke-traditioneltmaskuline eller til andre køn på tværs af de traditionelle: altså til diverse 'fremmede' indflydelser som amerikansk underholdning, reality-tv, tv-shows eller internationale bestseller-fænomener inden for litteratur, kunst og musik. Mange - som f.eks. kulturminister Brian Mikkelsen (se Kirsten Thisted i dette bind) giver også udtryk for, at selve 'danskheden' er truet. Denne artikel vil argumentere for, at de mere eller mindre dansksprogede danskere - fra Nørager eller Nairobi - faktisk har mange fælles referencer: De fleste af dem er bare anderledes end i de generationer, der blev født før den globale massekultur for alvor brød igennem med ugeblade, tv og pop-musik i perioden efter 1945. Selv er jeg født i 1952 på landet i små kår og blev den første student i min familie. Vi fra intelligensreserven (betegnelsen for sociale mønsterbrydere dengang) blev påtvunget borgerskabets dannelsesideal, som var så uanfægtet kanoniseret, at en eksplicit kanon slet ikke var nødvendig. Det er den åbenbart i dag. Det har ikke været svært at skaffe medlemmer til de statslige udvalg, der i 2004 udgav undervisningskanon for litteratur og i 2006 barslede med kanonlister for flere kunstarter. En del af reaktionen på de statslige udspil har været opstilling af alternative kanonlister snarere end diskussioner eller definitioner af selve den kanoniske tankegang. I den situation kan det være givtigt at anlægge et historisk perspektiv på den senmodernitet, der er en foreløbig kulmination af en kulturkamp, der begyndte i perioden omkring den franske revolution med konservative tænkere som Edmund Burke, der ønskede at mane til forsvar for en traditions- og nationstænkning inden for kunst og kultur i bredeste forstand. De så massen, populariseringen og feminiseringen som en farlig tendens, der netop kunne underminere Nationen, Kulturen og Kunsten fordi de fælles referencerammer blev underminerede af det (for) populære (Klitgaard Povlsen 2005). Men det populære er jo netop det, der kan blive en fælles referenceramme for mange.

Den generation af unge, der i dag er i tyverne har mange fælles referencerammer og bortset fra Bamse og Kaj og Andrea er kun få af dem knyttet til det snævert nationale: De kender Beverly Hills 90210 (Klitgaard Povlsen 1999), Klovn (og koncept-tv), Tour de France, mytiske rollespil og H. C. Andersen. Kun den sidste kan kanonlisterne også kapere - Andersen er blevet en af de danske nationalhelte, selvom han var og er både populær og en anderledes mandetype end den traditionelle maskuline kunstnerhelt. På den ene side vil jeg altså hævde at kanon og kulturkamp er og længe har været et forsøg på at inddæmme populærkulturen, på den anden side trænger denne sig hele tiden på og igennem barriererne, netop på grund af populariteten. I det paradoks kommer også kønnet, som vi senere skal se, til at spille en væsentlig rolle.

\section{KANON}

Ordet kanon kommer fra græsk og betyder rettesnor eller regel. I den kristne kultur 
bruges ordet som betegnelse for de autentiske eller xgte dele af bibelen og for teksten til den del af messen, hvor vin og oblat forvandler sig til Kristi blod og kød. De katolske helgener bliver stadig kanoniserede, dvs. kommer på den officielle helgenliste. Inden for æstetikken brugtes ordet i værket Kanon af den anerkendte græske billedhugger Polykleitos (455-420 f. Kr.), der argumenterede for, at hans egen statue Spydbæreren kunne betragtes som en rettesnor (kanon) for fremstillingen af den ideale mandsfigur. Ideel fordi figuren lagde hele kropsvægten på det ene ben, så han indtog en 'naturlig' stilling. Kanon betyder altså regler for det forbilledlige, det smukke og det natur-imiterende. Det betyder det også, når vi synger $\mathrm{i}$ kanon og skal sætte ind på skift efter hinanden på rette tid og tone, men i den musikalske forstand er kanon også en fler- eller mangestemmig sang, der både baserer sig på rytmens rettesnor og på melodistemmens forskellighed. Denne både-og tankegang af enshed og forskelssætning har været nedprioriteret $\mathrm{i}$ de kendte kanondebatter både før og nu, herhjemme og anderswo, f.eks. i USA. Men den er en del af kanon-begrebet og peger precist ind i det paradoks af det smalle og det bredere, som jeg beskrev ovenfor i inddæmningsmetaforen.

Den første store kanondiskussion af mange i Europa fandt sted i slutningen af 1600-tallet og blev ført mellem Les Ancien, der med f.eks. Boileau gik ind for at fremhæve antikken som et ideal, man aldrig kunne nå, men hvis regler man kunne efterligne - og les Modernes, der f.eks. med Dubos og svejtserne Bodmer og Breitinger begyndte at kritisere den klassiske retorik og som dannede afsæt for en ny sans for samtidens storhed og for en mere subjektiv oplevelse af kunst, som man kan se i Kants Kritik der Urtheilskraft fra 1790. Indbildningskraft blev et kernebegreb for vurderingen af kunst i 1700-tallet og en bebuder af det senere romantiske kunstgeni. Indtil da havde det antikke ideal stået uanfægtet: $\mathrm{Nu}$ blev sansen for folkesprog, kunst og andre naturer end de antikke vakt over det ganske Europa - og i Amerika. Vurderingen af litterær kvalitet skiftede. I stedet for at være en betegnelse, der målte samtidens forfattere mod antikkens Homer og andre, blev litterær kvalitet også ensbetydende med noget nyt, noget anderledes og noget tidssvarende. En tilsvarende bevægelse skete inden for andre kunstarter og den nye opfattelse af kvalitet betød, at nye temaer som f.eks. hverdagen, familien og landskabet kom i centrum for kunstnerisk bearbejdning.

Den anden bølge i kanondiskussionen kom omkring år 1800, hvor de fleste 'civiliserede' lande opbyggede eller reformerede deres universiteter til at blive nationale vidensinstitutioner. Samtidig kan man se de første nationale litteraturhistorier opstå og da de nødvendigvis må selektere i mængden bliver de også de første skitser til nationale kanonforståelser: I Danmark Nyerup og Rahbeks Bidrag til den danske Digtekunsts Historie fra 1812, men allerede i 1774 kom Wartons History of English Poetry og i 1799 forste bind af Eichhorns Literaturgeschichte der Literatur. De afløste universal-litteraturhistorier for Europa eller for hele verden og så kun på litteratur skrevet på det nationale hovedsprog. Fokus på hovedsproget betød, at en række dialektog minoritetssproglige værker med et slag forsvandt ud af den kulturelle bevidsthed, i Danmark f.eks. den ret store tysk-danske litteratur, i England f.eks. den gxliske (Lerrsen 1999). I lyset af det romantiske paradigme og fokus på kunstneren som nyskabende geni vurderedes den rene fiktion også højere end f.eks. rejselitteratur og historieskrivning, som ellers havde indgået i forståelsen af 'rigtig' litteratur. I dag er det en selvfølgelighed, men det er en konstruktion af nyere dato, der marginaliserede den mere faktuelle eller biografiske litteratur, der var blevet populær i 1700-tallet. Med et slag forsvandt mange kvinder og mange flerkulturelle forfattere ud af en fælles kulturel bevidsthed. Kvinder havde oversat, 
skrevet rejselitteratur, portrætter, personlig lyrik, dagbøger osv. og havde deltaget i uformelle uddannelsesforløb og netværk, men blev nu udelukket fra de formelle uddannelsesinstitutioner.

I denne optik er kanon en nationalromantisk konstruktion, knyttet til det nationale sprog og til en opfattelse af kunstneren som et geni og en slags helt. Det gav kvalitetsbegrebet endnu et tvist. Til et kvalitetsbegreb, der fokuserede på det nye kom også et fokus på indholdet: Det nationale og den lokale mytologi og historie kom i fokus - tænk bare på Oehlensschlägers Guldhornene, der kan stå som det danske, paradigmatiske eksempel på den udvikling (Sanders 2006).

\section{HAROLD BLOOMS KANON}

I nyere tid kom kanondebatten til Danmark fra USA under overskriften 'Cultural War'. Bertel Haarder nedsatte som undervisningsminister i 1992 et kanonudvalg. I 1993 fik skoleloven en paragraf, der indskærpede skolens pligt til "at gøre eleverne fortrolige med dansk kultur" og siden promoverede udvalgsmedlem Hans Hauge Harold Blooms The Western Canon fra 1994, som blev omdiskuteret i hele den vestlige verden. Bloom foreslog 26 kanoniske forfattere "in our culture", hvor "Things have fallen apart, the center has not held, and mere anarchy is in the process of being unleashed..." (s. 1). Bloom lægger ikke skjul på, at hans projekt er et forsøg på at rekonstruere en regel, der allerede ER faldet. Han er elegisk og nostalgisk, han ønsker at restaurere et kulturlandskab, der for længst er blevet eroderet af nye kulturprodukter, af ny publikumssøgning og af en forskning, der har belyst felter, der før har været ukendte eller kendte fra andre sider - f.eks. i gender, queer- og cultural studies. Bloom forsøger at fastfryse et snapshot fra en udefinerlig fortid - fra engang til nu og hans kanonliste ligner dermed de aktuelle danske forsøg på at skrive lister, der er almengyldige om end nok ikke eviggyldige.

Bloom fokuserer på 26 forfatterskaber, 12 engelsksprogede, en italiensk, en spansk, 3 spansk-portugisiske, 3 franske, 3 tyske, en russer og en nordmand. 21 mænd, 5 kvinder - alle engelsksprogede. Gode forfattere, der i praksis længe har stået på mange sprog og nationers kanoniske lister og undervisningspensa. Alle er vestlige og hvide og majoriteten er af hankøn. Det lægger Bloom ikke skjul på og han undskylder ingenting. Han lægger heller ikke skjul på, at når han ser et behov for en litterær kanon, så er det fordi litteraturen er truet af MTV og andre nye medier (s. 517):

Finding myself now surrounded by professors of hip-hop; by clones of Gallic-Germanic theory; by ideologies of gender and of various sexual persuasions; by multiculturalists unlimited, I realize that the Balkanization of literary studies is irreversible.

Til de kvalitative og sproglige skift er der senest omkring 1850 kommet endnu et skift: Grænsen mellem det populære, det massekulturelle og det finkulturelle har erstattet en grænse mellem det folkelige og det fine, som vi kender langt tilbage (Burke 1978). Når det litterære felt (eller de andre 'klassiske' kunstarter) bliver presset af nye medier, făr vi en mediepanik om smagens og sædernes forfald - og en kanon-diskussion. Begge diskussioner abonnerer implicit på kvalitet, køn, klasse, nationalitet og etnicitet - det vender jeg tilbage til. Bloom forudser, at litteraturvidenskab snart vil henhøre under afdelingen for klassiske studier, mens cultural studies og medievidenskab overtager humaniora og konkluderer:

If literary canons are the product only of class, racial, gender and national interests, presumably the same should be true of all other aesthetic traditions, including music and the visual arts. (s. 527) 
Bloom mener, at der skal mere til at skabe tradition og kanon som f.eks. talent, sprogsans, disciplin og kulturel fingerspitzgefühl, men det er svært at være uenig med det ovenstående, som man dog også kan se som en registrering af en historisk udvikling, som der i sig selv intet fatalt er i.

\section{KØN OG MODERNISME}

De især kvindelige litterater, der interesserede sig for kvindelige forfattere i 1970erne, fik netop energi fra en kanon-kritik: D.H. Lawrence var fejllæst, Charlotte Brontës mest interessante kvindefigur var ikke Jane Eyre, men The Mad Woman in the Attic, titlen på Susan Gilbert og Sandra M. Gubars indflydelsesrige værk om realistisk, engelsk litteratur fra 1979, som kulminerede i opfordringen til kvindelige forfattere om at tage pennen/penis i egen hånd. Bogen sluttede med naturalismen og det moderne gennembrud i slutningen af 1800-tallet. Den frembrydende modernisme med dens fokus på form og fragment blev set som et maskulint komplot mod de kvindelige forfattere. Når de netop havde opnået mesterskab inden for realistisk litteratur, flyttede den maskuline avantgarde ind i modernisme og nye formeksperimenter. Gilbert og Gubar anfegtede ligefrem modernismens projekt og satte spørgsmålstegn ved Virginia Woolfs forfatterskab, fordi det var så formfornyende.

Tonen blev dog ganske anderledes i deres langt mindre indflydelsesrige store tre binds udgave af No Man's Land 19881994, der analyserer 1900-tallets engelske og amerikanske litteratur, skrevet af kvinder. Indgangsspørgsmålet lyder denne gang: Er pennen en metaforisk pistol? Krigsmetaforikken er gennemgående, det er en kønskamp på sprogets slagfelt, de viser. De henviser nu som en slags forklaring til den modernistiske Virginia Woolf, som de i det tidligere værk lagde afstand til. Men betegnende nok ikke til et af hendes skønlitterære værker, derimod til essayet $A$ Room of One's Own, hvor hun skriver:
Toward the end of the $18^{\text {th }}$ century a change came about which, if I were rewriting history, I should describe more fully and think of greater importance than the Crusades or the War of Roses. The middle-class woman began to write (s. 68)

Det er den samme udvikling Pil Dahlerup har vist i Norden med sine to bind af Det moderne gennembruds kvinder fra 1983. Middelklassekvinderne begyndte (også) at skrive og at offentliggøre deres produktioner $i$ anden halvdel af 1800tallet, og denne litteratur skabte et ubehag hos mange mandlige forfattere - ikke kun fordi mange af de kvindelige forfattere faktisk var gode realister, men fordi de var så mange og fordi den form for feminitet, som disse forfatterskaber repræsenterede, oplevedes som truende - som Pil Dahlerup også viser. Sammen med kvinderne kom andre grupper til: Skolelærere og jernbanefunktionærer. Den realistiske og naturalistiske skrivefacon bød sig til for grupper, der ikke før havde fattet pennen. Gilbert og Gubar hober eksempler op på, hvor mange mænd, der klager over denne damelitteratur, denne feminisering af kulturen og det offentlige rum. I deres fremstilling blev kønnet og seksualiteten 1900-tallets vigtigste litterære slagmark for både mænd og kvinder, for både hetero-, bi- og homoseksuelle - betegnelser som blev dannet i samme periode. Krigen om seksualiteten og kønskampen blev også i deres synsvinkel en vigtig del af det modernistiske projekt - for både mandlige og kvindelige forfattere. Fra 1. verdenskrigs No Man's Land (bind I) mellem skyttegrave til 2. verdenskrigs 'blitz' mod kvindelige forfattere. I Gilbert og Gubars fremstilling er litteraturhistoriens heltinder dem, der bekender sig til en kvindelitterær arv og som eksperimenterer med deres særligt kvindelige forhold til sproget - a la Helene Cixous' teorier om kvindeskrift, f.eks. i At komme til skriften fra 1977 (1985). En af grundene til den ringe indflydelse dette faktisk imponerende trebinds- 
værk fik, var at Gilbert og Gubar bidrog til at grave skyttegravene mellem kønnene endnu dybere. Men de viser samtidig implicit, at det store læsende kvindelige og nydannede publikum ikke bare havde lært realismens kode og var blevet berørt af naturalismens seksualitetsdiskussioner. De var også begyndt at skrive selv - som det sker for mange læsere af populærlitteratur som kærlighedsromaner eller kriminallitteratur også i dag (Radway 1984).

Fordelingen med kvinden som læser og manden som forfatter-producent var historisk produceret i tiden lige før 1800. Friedrich Kittler viser overbevisende i Aufschreibesysteme 1800/1900 fra 1985, hvordan 1700-tallets kvindelige forfattere og lærde kvinder blev uddannet af deres fædre med hjælp fra huslærere. Men i slutningen af 1700-tallet skete et grundlæggende skrift. Faderens rolle som pædagog og uddannelsesansvarlig i hjemmet blev overtaget af den ømme mor, der overtog læseindlæringen fra den ofte hårdtslående huslærer og således med mund-til-mund-metoden lærte sine børn 'die Muttersprache', mens faderen sørgede for 'das Vaterland', økonomien og produktionen af kunst. Det affødte en storproduktion af pædagogiske traktater, der ofte var inspireret af Jean Jacques Rousseaus reformpædagogiske værk Emile fra 1762. I slutningen af 1700-tallet henvendte de pædagogiske skrifter sig ikke til den mandlige prdagog, som Rousseau havde gjort, men til den følsomme og kærlige moder, der havde taget alfabetiseringen i egen hånd. Den tyskskrivende danske Friederike Brun, f. Münter (1765-1835) er et godt eksempel på Kittlers beskrivelse af et kønsskifte i forhold til læse- og sprogindlæring og på, at de veluddannede og lærde kvinder fra 1700-tallet bliver sjældnere i begyndelsen af 1800-tallet. Friederike Münter havde i København fået en udmærket, uformel uddannelse af sin præstefar og af hjemmets huslærer. Hun gik allerede i puberteten efter en karriere som forfatter og fik den også. Hun blev gift og fik børn og fortsatte sit forfatterskab. Hendes egne døtre derimod blev undervist af deres mor og mange skiftende huslærere med vægten lagt på sang, dans, tegning og klaverspil. De blev gift og to af dem blev i samtiden af f.eks. Johan Ludvig Heiberg og Jens Baggesen fremhævet som romantiske kvindeidealer, netop fordi de var så smukke og tavse og kun trådte frem med klaverspil og sang (Klitgaard Povlsen 2001a, 2001b, 2000). Mellem mor og døtre var sket et grundlæggende skift i uddannelsesniveau og i offentlig fremtræden. Det var meget tidstypisk også i Danmark.

ABC'er og pædagogiske hjælpemidler blev masseproduceret netop fra midten af 1790erne som redskaber for de mødre, der nu burde tage læseindlæringen i deres egen legende og følsomme hånd, så sønnerne og enkelte af døtrene siden kunne fortsætte i de mere offentlige skolesystemer. Kvinderne læste, mændene skrev, kvinderne slugte den populære fiktionslitteratur, mændene eksperimenterede med den elitære kunst, men følte sig samtidig inficeret af den feminitet, som så at sige klæbede til sproget, til tungen, fordi sprogindlæringen var så tæe forbundet med moderskabet. Denne feminisering knyttede sig til indhold og følelser og en undvigemekanisme blev at fokusere på formen og sprængningen af den. En form for eksperiment, som også stod i modsætning til den massekultur $\mathrm{i}$ form af store oplag af trykte bøger, tidsskrifter, magasiner og serieproduceret litteratur, som opstod i midten af 1800-tallet med f.eks. Eugen Sue og Dickens som banebrydere. De skrev feuilletonlitteratur, der udkom hver uge eller hver måned og som blev en god forretning for mange udgivere. Deres primære publikum var middelklassens læsende kvinder. Den slags spændende realisme blev altså hurtigt forbundet med et kvindeligt publikum, et mere uddannet publikum af underklassemænd og med massekulturen som sådan. Altså flyttede kunsten og med den de professionelt arbejdende mandlige forfattere sig væk fra det 
populære, det massemediale og det feminine. Modernismen i litteratur og billedkunst blev den nye elitære og heroiske udfordring, mens mange læste stadig flere blade, hefter og seriebøger (Povlsen 1996).

Andreas Huyssens bog After the Great Divide: Modernism, Mass Culture, Postmodernism fra 1986 handler om køn og modernisme, især kapitlet "Massekulturen som kvinde: Modernismens Anden" (Ørum og Svane 1991). Huyssen tager udgangspunkt i den kvindelige læser, f.eks. Flauberts Emma Bovery, der "elskede at læse romaner". Emma Bovarys forfatter blev anerkendt som en af modernismens fædre. Huyssen refererer Sartre for at mene, at Flaubert feticherer sin egen imaginære feminitet, mens han er fjendtlig overfor virkelighedens kvinder. Det ser han som en almindelig og typisk reaktion for den mandlige modernist: Den mandlige forfatter er ikke en rigtig mand som f.eks. en industrifyrste eller naturvidenskabsmand. Når Flaubert siger "Mme de Bovary, c'est moi", så skriver Huyssen med Sartre: nej, der er mindst kønnet til forskel.

Med Adorno og Horkheimers ord fra 1948 er "massekulturen, i sit spejl, altid den smukkeste i landet" (s. 94) og Huyssen viser, hvordan denne feminisering af massekulturen sker igen og igen fra midten af 1800-tallet indtil videre. Billedet af den rasende masse som kvindelig findes allerede $\mathrm{i}$ Edmund Burkes kritik af den franske revolution fra 1790, hvor optoget mod Versailles for ham at se består af lutter ludere - eller underklassekvinder (Klitgaard Povlsen 2005). Huyssens eksempel er Gustave le Bons indflydelsesrige La Psychologie des foules (Massernes psykologi fra 1895): "Masserne er overalt kendetegnet af kvindelige egenskaber..." "Ligesom kvinder går den straks til yderligheder...". Som Huyssen konkluderer: "alt det der nedvurderes konsekvent bliver mærket som kvindeligt..." (s. 100). Massen og underklassen blev og bliver set som feminin.

Huyssen ser således modernismen som en reaktion på massekulturen og varegørelsen af en kunst, der blev modtaget med tørst af et kvindeligt og et uddannet publikum. Modernismen projekt blev bl.a. at producere en kunst som kun den veluddannede, typisk mandlige, kender kunne læse og goutere. Det autonome kunstværk, fri for enhver mistanke om kommercialisme, eksperimenterende på linje med naturvidenskabens laboratorieforsøg. Resultatet, siger Huyssen, er en maskulin mystik. Huyssen var dog i 1986's glade postmodernisme optimist og mente, at problematiseringen af grænserne mellem det elitære og det populære også ville betvivle de traditionelle grænser mellem kønnene og dermed jage det misogyne modernistiske projekt på tilbagetog.

Sådan gik det ikke set med mine øjne. I stedet fik vi retraditionalisering, kanondiskussion og en massiv kønsulighed - især på kunstens område! Min konklusion er, at kønnet er kompliceret og er blevet en af mange arenaer, hvor mange forskelle krydser hinanden i forhandlinger om fastlæggelser af betydning. Køn står ikke alene i dette krydsfelt, men traverseres af 'neutrale' kvalitetskriterier og af nationalisme og massekultur. Hvor outdated det måske måtte lyde, spiller klassetilhørsforholdet og forståelsen af massen som feminiseret også stadig en rolle, selvom smagssociologer som Pierre Bourdieu og Anthony Giddens har svært ved at argumentere empirisk for det! I dette krydsfelt er de danske kanoner et forsøg at fastlægge adkomsten og traditionen og den adkomst er i 2006-udgaven stærkt præget af det danske sprog og af en heroisk og maskulin kunstnermyte som modsætning til massemediernes kommercialisme.

Hvad kan man så gøre? Hans Hauge udtalte $\mathrm{i}$ anledning af kanondebatten $\mathrm{i}$ januar 2006, at de populære kunstværker ingen kanonisering behøvede fra statslig side, for de var allerede kanoniseret af markedet. Og markedet er, som vi har set, i den almindelige opfattelse domineret af et kvindeligt publikum og andre grupper uden egentlig 
eller professionel kunstnerisk dannelse. Modtrækket kan kun være enten at undsige kanonlisterne eller at lade dem implodere ved at lave så mange kanonlister som muligt over alt muligt.

\section{LITTERATUR}

- Bloom, Harold (1995, 1994): The Western Canon. MacMillan, London - Burke, Peter (1978): Popular Culture in Early Modern Europe. Harper and Row, New York - Cixous, Helene (1985): At komme til skriften. Rosinante, Charlottenlung - Dahlerup, Pil (1983): Det moderne gennembruds kvinder. Gyldendal, København

. Gilbert, Susan and Sandra M. Gubar (1979): The Mad Woman in the Attic. Yasle University Press, New Haven

- Gilbert, Susan and Sandra M. Gubar (19881994): No Man's Land. 1-3. Yasle University Press, New Haven

· Huyssen, Andreas (1991, 1986): Massekulturen som kvinde: modernismens Anden. Tania Ørum og Marie Louise Svane, red.: Kon og moderne tider. Tiderne Skifter, København, s. 89-119

- Kittler, Friedrich (1987, 1985): Aufschreibesysteme 1800/1900. Wilhelm Fink, München

- Klitgaard Povlsen, Karen (1996): "Skrifter til tiden og Det moderne gennembruds billedblade". in Klaus Bruhn Jensen red.: Dansk Mediehistorie 1, 1840-1880. Samleren, København, s. 49-68, 176187
- Klitgaard Povlsen, Karen (1999): Beverly Hills 90210. Klim, Aarhus

- Klitgaard Povlsen, Karen (2000): Marmorkrop. Rube Gade og Marianne Raakilde Jespersen red.: Krop og Estetik. Tiderne Skifter, København, s. 210-238

- Klitgaard Povlsen (2001): Friederike Brun på Sophienholm. Jeppe Tønsberg red.: Sophienholm. Lyngby-Bogen, Lyngby-Taarbæk, s. 33-66

- Klitgaard Povlsen, Karen (2001): Standsningens attitude i krop og tekst. Elin Andersen og Karen Klitgaard Povlsen red.: Tablean - Det sublime øjeblik. Klim, Aarhus, s. 93-117

- Klitgaard Povlsen, Karen (2005): Kulturrevolution og Kulturkamp: 1789 og reaktionen i England. Karen Klitgaard Povlsen og Anne Scott Sørensen, red.: Kunstkritik og Kulturkamp. Klim, Aarhus, s. 16-33

- Lerrsen, Joep (1999): For a Post-.Foucauldian Literary History. Configurations 1999, 7: 227-245

- Radway, Janice (1984): Reading the Romance. Verso, London

- Sanders, Karin (2006): "Upon the Bedrock of Material Things": The Journey to the Past in Danish Archeological Imagination. Karen Klitgaard Povlsen, red.: Northbound - Travels, Encounters, Constructions 1700-1830. Aarhus University Press: in press, Aarhus

Karen Klitgaard Povlsen, Ph.d., mag.art. Lektor på Institut for Informations- og Medievidenskab på Aarhus Universitet. 